\title{
National record-linkage study of hospital admissions for schizophrenia in childhood and adolescence in England
}

\author{
Olena Seminog ${ }^{1}\left[\right.$ U $\cdot$ U Hoang $^{2} \cdot$ Michael Goldacre $^{1} \cdot$ Anthony James $^{3}$
}

Received: 6 July 2020 / Accepted: 31 May 2021 / Published online: 18 June 2021

(c) The Author(s) 2021

\begin{abstract}
Background There is a lack of information on changes in hospital admission rates for childhood-onset schizophrenia (COS), or on patient characteristics, to inform clinical research and health service provision.

Aims To report age- and sex-specific incidence rates of hospital admissions and day patient care for schizophrenia (ICD-10 F20) and non-affective psychosis (ICD-10 F20-29), by year of occurrence and age, in childhood and adolescence.

Methods Population-based study using person-linked data for England (available 2001-2016); time-periods in single years and 4-year groups.

Results Hospitalised incidence for schizophrenia increased with increasing age, from 0.03 (95\% confidence interval (CI) $0.02-0.05)$ and $0.01(0-0.01)$ per 100,000 in, respectively, males and females aged 5-12 years, to 3.67 (3.44-3.91) in males and $1.58(1.43-1.75)$ in females aged 13-17 years. There was no gender difference in hospitalised incidence rates in children aged 5-12, but in 13-17 years old, there was a male excess. Rates for schizophrenia were stable over time in 5-12 years old. In ages 13-17, rates for schizophrenia decreased between 2001-2004 and 2013-2016 in males, from 6.65 (6.04-7.31) down to $1.40(1.13-1.73)$, and in females from $2.42(2.05-2.83)$ to $1.18(0.92-1.48)$. The hospitalisation rates for schizophrenia and non-affective psychosis, combined, in 13-17 years old decreased in males from 14.20 (13.30-15.14) in 2001-2004 to 10.77 (9.97-11.60) in 2013-2016, but increased in females from 7.49 (6.83-8.20) to $10.16(9.38-11.00)$.

Conclusions The study confirms that childhood-onset schizophrenia is extremely rare, with only 32 cases identified over a 15 -year period in the whole of England. The incidence of schizophrenia and non-affective psychosis increased substantially in adolescence; however, the marked reduction in the proportion of those diagnosed with schizophrenia in this age group suggests a possible change in diagnostic practice.
\end{abstract}

Keywords Schizophrenia $\cdot$ Childhood onset $\cdot$ Children $\cdot$ Epidemiology $\cdot$ Electronic records

\section{Introduction}

Childhood-onset schizophrenia (COS), defined as onset before 13 years of age, is a serious, psychotic disorder with high rates of morbidity, mortality, and poor recovery $[1$, 2 ] —only $50 \%$ partially remit at 42 -year follow-up [3]. In

Olena Seminog

Olena.seminog@ndph.ox.ac.uk

1 Unit of Health-Care Epidemiology, Big Data Institute, Li Ka Shing Centre for Health Information and Discovery, Nuffield Department of Population Health, University of Oxford, Old Road Campus, Oxford OX3 7LF, UK

2 Nuffield Department of Primary Health Care Sciences, University of Oxford, Oxford, UK

3 Department of Psychiatry, University of Oxford, Oxford, UK
England, schizophrenia accounts for a quarter of all psychiatric admissions in the age group 10-18 years, and the admission rate increases with age [4]. It is generally thought that $\mathrm{COS}$ is very rare; however, epidemiological estimates of the incidence and prevalence of COS are sparse, which is a limitation given that these children require high levels of health resources due to the level of disabilities.

In this study, we describe the demographic characteristics and hospitalised incidence rates for COS and early-onset schizophrenia (EOS) — schizophrenia arising in adolescents between the ages of 13-17 years-alongside a broader category of non-affective psychosis for both age groups.

National datasets of inpatient electronic records are a valuable source of information on rare diseases. This study used linked national routine electronic patient records, an alternative methodology to the use of disease registries 
or cohort studies using personal follow-up of people with psychiatric conditions. We report on hospitalised incidence rates, covering inpatients and day-cases, for COS and EOS in England for the period 2001-2016 by sex. To set this in a wider historical context, we also consulted archived tables from the Oxford Record Linkage Study (ORLS) covering trends in psychiatric-service contacts for schizophrenia in the former Oxford NHS Region from 1966-1993 [5].

\section{Methods}

\section{Datasets}

\section{Hospital episode statistics}

We analysed a linked dataset of Hospital Episode Statistics (HES) for England from 2001 to 2016. The population of England was 55 million in 2016. In England, treatment in the National Health Service (NHS) hospitals is free. All hospital admissions and day-cases are included in the HES dataset and were called inpatients in this paper. The clinical diagnoses in HES are coded using the International Classification of Diseases (ICD). Each HES record contains information on the primary diagnosis, secondary diagnoses, demographic characteristics, and administrative variables such as dates of admission and discharge. Socio-economic status is measured using the patients' area-level Index of Multiple Deprivation (IMD), which is a standard measure of neighbourhood deprivation recorded in HES. Ethnicity is self-reported in HES. Hospital records for every patient in the dataset were linked together in time-sequenced order of admissions. The record linkage was done centrally by NHS Digital.

\section{Oxford Record Linkage Study (ORLS)}

We also included historical data from a subset of the Oxford Record Linkage Study (ORLS), available as aggregated statistical tables held in the Unit of Health-Care Epidemiology (UHCE), University of Oxford. The ORLS is a regional dataset for the former Oxford NHS Region [5]. The ORLS data included outpatients (ambulatory care, provided by psychiatrists) from 1975 to 1993 as well as inpatients and day case care. Using these data enabled us to add historical context for the current study, and also acted as a sensitivity test for the national dataset of routine patient data, which is limited to hospital inpatient contacts only. The ORLS data and the national HES dataset were compiled independently of each other and, to that extent, each can be used to corroborate the findings in the other. The ORLS covered data collected from 1966. In addition, from 1975-1993, in the county of Oxfordshire, it included specialist psychiatric data collection on all ambulatory patients. The ORLS tabulations are available in quinquennial age groups $(0-4,5-9,10-14$ years). Therefore, we included children aged 5-14 years, as we were not able to restrict to under 13 years. The cumulative population denominators for the 44-year study period, expressed in person-years, were 699,900 in males and 664,100 in females.

\section{Study design}

The analyses in the national study included all children aged 5-17 years who had a hospital record with a diagnosis of schizophrenia and non-affective psychosis. We included people who were admitted to a hospital with schizophrenia recorded as the primary diagnosis, regardless of hospital specialty. This was done to achieve maximum coverage of all COS cases nationally. It is possible that some children, in particular, those with less severe presentations, might have been managed in a paediatric ward under the joint care of a paediatrician and a child psychiatrist.

\section{Case identification}

The cases of COS were defined using the ICD codes. In the national dataset, we used the ICD-10 codes F20 for schizophrenia and F20-29 for the broader ICD diagnostic block termed "schizophrenia, schizotypical and delusional disorders". We refer to the latter block, in what follows, as nonaffective psychosis. For the historical data from Oxfordshire, we used the corresponding diagnostic block codes from the earlier revisions of the ICD.

\section{Consent statement}

The datasets are anonymous; patients and contact details cannot be identified. This data-based study did not involve informed consent from participants.

\section{Data analysis}

For the all-England study, we calculated age-specific incidence rates for schizophrenia in two age groups, 5-12 and 13-17 years. The rates were calculated for every calendar year between 2001 and 2016, which is the year range for which the datasets were available. Because of the small number of events in some age groups, to obtain more statistically robust results, we have also grouped years in four equal intervals, 2001-2004, 2005-2008, 2009-2012, and 2013-2016. The annual rates and rates for the broader timeperiods were calculated by dividing the number of cases of schizophrenia at each age by the total number of children in England at that age. Age-specific population denominators were obtained from the Office for National Statistics. 
In ORLS, the incidence rates were calculated by dividing the total number of cases of schizophrenia in the specified period of time by the average population in those years and in the relevant age, and by the number of years.

The rates were calculated for males and females separately and expressed per 100,000 age- and sex-specific population. The corresponding $95 \%$ confidence intervals were calculated assuming a Poisson distribution. We only included the first-ever record of diagnosed schizophrenia for each individual, which is the closest available measure of population incidence. If an individual had two or more admissions in one calendar year or in different calendar years, only the first one was included in the analysis.

We reported on the rates of previous hospital admissions for any psychiatric disorder in males and females with COS, recorded as either main or secondary diagnosis. We used the ICD-10 range of codes F00-F19 and F30-F99 to identify admissions for previous psychiatric conditions.

We calculated the proportion of people with COS diagnosed with autism, using the ICD-10 code F84 recorded in any position on the hospital discharge record.

\section{Ethical approval}

The Central and South Bristol research ethics committee (No 04/Q2006/176) approved the building and analysis of the dataset of anonymised records for a multi-purpose programme of research by the Unit of Health-Care Epidemiology, University of Oxford.

\section{Results}

\section{English national data}

\section{Study population characteristics}

Over the course of 15 years, in a total all-England population of 55 million people, we identified 32 inpatient cases of childhood-onset schizophrenia in children aged 5-12 years, and 1,354 inpatient cases of early-onset schizophrenia in adolescents aged 13-17 years (Table 1). There was no gender difference in COS, but higher incidence rates of EOS in males than females (Table 1). More than $67 \%$ of males and $80 \%$ of females with COS were from the two lowest socio-economic quintiles as measured by the IMD. Ethnicity was recorded for $75 \%(\mathrm{n}=9$ people) males and $87 \%(18)$ females with COS: of these, 33\% (3) of males and 39\% (7) of females were White, $22 \%$ (2) of males and $28 \%$ (5) of females were Black (Table 1). The distribution of cases by place of residence showed that 50\% (6) of males and $25 \%$ (5) of females with COS lived in London (Table 1). Among
COS patients, 50\% (10) of females and none of the males had a recorded diagnosis of autism. Most children with COS, $83 \%$ (10) males and $80 \%$ (16) females, had a record of previous hospital admission for another psychiatric condition.

\section{Changes in incidence rates and age-specific rates of COS and EOS, 2001-2016}

The number of cases of COS varied from year to year, with no cases in some years (Table 2 and Supplementary Tables 1 and 2). For males with COS, the incidence rates between 2001 and 2016 were very low, but stable as evident from the overlapping confidence intervals for rates of 0.03 (95\% CI 0.01-0.05) per 100,000 in 2001 and 0.07 (0.01-0.27) in 2016, and for females $0.04(0.00-0.23)$ in 2002 (no cases were recorded in 2001) and $0.04(0.00-0.22)$ in 2016 (Table 2). After these small numbers were combined in equal time-periods to yield more power, no statistically significant changes in rates were observed (Table 3). Likewise, there was no statistically significant increase in rates of non-affective psychosis (F20-F29) - the confidence intervals overlapped for rates calculated in individual years, as well as time-periods: for males from 0.27 (0.11-0.56) in 2001 to $0.51(0.28-0.86)$ in 2016 and for females from $0.24(0.09-0.53)$ in 2001 to $0.73(0.44-1.14)$ in 2016 (Table 2). When rates were calculated in time-periods, they were $0.32(0.22-0.45)$ in 2001-2004 and $0.34(0.24-0.48)$ in 2013-2016 in males and $0.32(0.21-0.45)$ and 0.50 (0.37-0.66), respectively, in females (Table 3 ).

The incidence rates of schizophrenia were overall higher in adolescence, which reduced over the study period. In 2001, in males aged 13-17, the incidence rate for EOS (F20) was 7.06 (5.82-8.48), which decreased during the study period to 0.77 (0.40-4.34) in 2016 (Table 2). In females with EOS, the incidence rates were 2.94 (2.14-3.93) in 2001 and 1.15 (0.67-1.84) in 2016 (Table 2). Similarly, in time-period analyses, the rates in males decreased from 6.65 (6.04-7.31) in 2001-2004 to 1.40 (1.13-1.73) in 2013-2016, and in females from $2.42(2.05-2.83)$ to $1.18(0.92-1.48)$, respectively (Table 3 ). The pattern for non-affective psychosis (F20-F29) showed decreasing rates in males aged 13-17, and increasing rates in females in the same age group, as revealed by time-period analysis. In males, the rates declined from $14.20(13.30-15.14)$ in 2001-2004 to 10.77 (9.97-11.60) in 2013-2016. In females, the rates were $7.49(6.83-8.20)$ in 2001-2004 and $10.16(9.38-11.00)$ in 2013-2016. (Table 3). The annual number of cases and hospitalised incidence rates for COS and EOS are provided as supplementary material (Supplementary Tables 1 and 2).

The number of schizophrenia cases increased with age (Fig. 1). For example, at ages 5, 6, and 7 years, there was only one case in females and no cases in males over the 15 years of observation. The great majority (90\%) of 
Table 1 Demographic characteristics of patients hospitalised with schizophrenia (F20) and non-affective psychosis (F20-29) from 2001 to 2016, by age group and sex

\begin{tabular}{|c|c|c|c|c|c|c|c|c|}
\hline \multirow{4}{*}{ Age group } & \multicolumn{4}{|l|}{$\mathrm{F} 20$} & \multicolumn{4}{|l|}{ F20-F29 } \\
\hline & \multicolumn{2}{|l|}{ Males } & \multicolumn{2}{|l|}{ Females } & \multicolumn{2}{|l|}{ Males } & \multicolumn{2}{|l|}{ Females } \\
\hline & $5-12$ years & $13-17$ years & $5-12$ years & $13-17$ years & 5-12 years & $13-17$ years & $5-12$ years & $13-17$ years \\
\hline & $\mathrm{N}(\%)$ & $\mathrm{N}(\%)$ & $\mathrm{N}(\%)$ & $\mathrm{N}(\%)$ & $\mathrm{N}(\%)$ & $\mathrm{N}(\%)$ & $\mathrm{N}(\%)$ & $\mathrm{N}(\%)$ \\
\hline Total number ( $\%$ of total) & 12 & 960 & 20 & 394 & 117 & 2940 & 152 & 1979 \\
\hline \multicolumn{9}{|c|}{ Number of people in different socio-economic groups and $\%$ of total, by IMD quintiles } \\
\hline Most deprived, Q1 & $5(42 \%)$ & $339(37 \%)$ & $8(40 \%)$ & $140(37 \%)$ & $38(32 \%)$ & $1023(36 \%)$ & $46(31 \%)$ & $676(35 \%)$ \\
\hline Q2 & $3(25 \%)$ & $227(25 \%)$ & $8(40 \%)$ & $98(26 \%)$ & $36(31 \%)$ & $681(24 \%)$ & $45(30 \%)$ & $420(22 \%)$ \\
\hline Q3 & 0 & $178(19 \%)$ & $2(10 \%)$ & $68(17 \%)$ & $18(15 \%)$ & $504(18 \%)$ & $25(17 \%)$ & $318(17 \%)$ \\
\hline Q4 & $2(17 \%)$ & $103(11 \%)$ & $2(10 \%)$ & $42(11 \%)$ & $12(10 \%)$ & $352(12 \%)$ & $21(14 \%)$ & $276(14 \%)$ \\
\hline Least deprived, Q5 & $2(17 \%)$ & $77(8 \%)$ & $28(10 \%)$ & $35(9 \%)$ & $13(11 \%)$ & $296(10 \%)$ & $13(9 \%)$ & $236(12 \%)$ \\
\hline \multicolumn{9}{|l|}{ Ethnicity } \\
\hline White & $3(33 \%)$ & $587(70 \%)$ & $7(39 \%)$ & $217(62 \%)$ & $59(61 \%)$ & $1675(66 \%)$ & $71(56 \%)$ & $1031(67 \%)$ \\
\hline Black & $2(22 \%)$ & $112(13 \%)$ & $5(28 \%)$ & $67(19 \%)$ & $17(18 \%)$ & $369(14 \%)$ & $27(21 \%)$ & $253(15 \%)$ \\
\hline Asian & $1(11 \%)$ & $67(8 \%)$ & $2(11 \%)$ & $29(8 \%)$ & $7(7 \%)$ & $214(8 \%)$ & $14(11 \%)$ & $132(8 \%)$ \\
\hline Other & $3(33 \%)$ & $69(8 \%)$ & $4(22 \%)$ & $35(10 \%)$ & $14(14 \%)$ & $296(12 \%)$ & $15(12 \%)$ & $174(10 \%)$ \\
\hline Not recorded & $3(25 \%)$ & $125(13 \%)$ & $2(10 \%)$ & $46(12 \%)$ & $20(17 \%)$ & $386(13 \%)$ & $47(17 \%)$ & $25(16 \%)$ \\
\hline \multicolumn{9}{|l|}{ Region of residence } \\
\hline North East & 0 & $60(6 \%)$ & $1(5 \%)$ & $19(5 \%)$ & $2(2 \%)$ & $139(5 \%)$ & $4(3 \%)$ & $62(3 \%)$ \\
\hline North West & $2(17 \%)$ & $183(19 \%)$ & $4(20 \%)$ & $64(16 \%)$ & $21(18 \%)$ & $557(19 \%)$ & $27(18 \%)$ & $323(16 \%)$ \\
\hline Yorkshire and Humber & 0 & $99(10 \%)$ & 0 & $29(7 \%)$ & $7(6 \%)$ & $224(8 \%)$ & $3(2 \%)$ & $139(7 \%)$ \\
\hline East Midlands & 0 & $76(8 \%)$ & $3(15 \%)$ & $34(8 \%)$ & $4(3 \%)$ & $204(7 \%)$ & $13(9 \%)$ & $147(7 \%)$ \\
\hline West Midlands & $1(8 \%)$ & $80(8 \%)$ & $3(15 \%)$ & $39(10 \%)$ & $12(10 \%)$ & $275(9 \%)$ & $16(11 \%)$ & $201(10 \%)$ \\
\hline East of England & 0 & $58(6 \%)$ & 0 & $28(7 \%)$ & $10(9 \%)$ & $193(7 \%)$ & $12(8 \%)$ & $159(8 \%)$ \\
\hline London & $6(50 \%)$ & $227(24 \%)$ & $5(25 \%)$ & $104(26 \%)$ & $44(38 \%)$ & $692(24 \%)$ & $41(27 \%)$ & $452(23 \%)$ \\
\hline South East & $2(17 \%)$ & $75(8 \%)$ & $2(10 \%)$ & $40(10 \%)$ & $13(11 \%)$ & $335(11 \%)$ & $23(15 \%)$ & $296(15 \%)$ \\
\hline South West & $1(8 \%)$ & $69(7 \%)$ & $2(10 \%)$ & $27(7 \%)$ & $4(3 \%)$ & $244(8 \%)$ & $11(7 \%)$ & $151(8 \%)$ \\
\hline
\end{tabular}

schizophrenia cases were in the age group 14 and older. The male-to-female ratio changed with age: up to the age of 13 there were more cases in females than males (20 vs 12). The male excess of schizophrenia and non-affective psychosis started from the age of 14 years (Figs. 1 and 2).

\section{COS incidence rates: Oxford Record Linkage Study}

In the 44 years between 1966 and 2010, there were 28 males and 8 females aged 5-14 admitted to hospital for schizophrenia. The average annual rates expressed per 100,000 residents aged 5-14 were 1.66 in males and 0.49 in females.

In the 18 years between 1975 and 1993, when data collection on all specialist psychiatric contacts (outpatients as well as inpatients) was available, there were 12 males and 5 females with schizophrenia aged 5-14. The average annual rates expressed per 100,000 residents aged 5-14 were 1.70 in males and 0.73 in females.

\section{Discussion}

\section{Summary of results}

Childhood-onset schizophrenia is very rare indeed. There were only 32 hospitalised cases of COS in in the whole of England (population 55 million) over a period of 15 years, with a hospitalised incidence rate in 2016 in males of 0.03 per 100,000 population and in females of 0.01 per 100,000 population. There was no significant difference between the male and female rates of COS, whereas a male excess started from the age of 14 years. In line with other studies, we reported that a large proportion of children with schizophrenia were of a low socio-economic status $[6,7]$. Half of females with COS were diagnosed with autistic spectrum disorder. There has been a striking reduction in the proportion of adolescents with psychosis (as judged by use of ICD codes F20-F29) receiving the diagnosis of schizophrenia (F20) during the period 2001-2016 (Supplementary Tables 1 and 2). The reason for this reduction in hospitalised 
Table 2 Number of admitted cases of schizophrenia (F20) and non-affective psychosis (F20-F29) and hospitalised incidence in the first and last year of the study, and average estimates for a period 20012016 , by age group and sex
Table 3 Time trends in hospitalised incidence rates for schizophrenia and nonaffective psychosis presented in four time intervals, with the corresponding number of events and population denominators by age and sex

\begin{tabular}{|c|c|c|c|c|c|}
\hline \multirow[t]{2}{*}{ Year } & \multirow{2}{*}{$\begin{array}{l}\text { Population } \\
\text { denomina- } \\
\text { tors }\end{array}$} & $\mathrm{F} 20$ & \multirow[t]{2}{*}{ Rates $(95 \% \mathrm{CI})$ per 100,000} & \multirow[t]{2}{*}{ No. of cases } & \multirow{2}{*}{$\begin{array}{l}\text { F20-F29 } \\
\text { Rates }(95 \% \mathrm{CI}) \\
\text { per } 100,000\end{array}$} \\
\hline & & $\mathrm{N}$ of cases & & & \\
\hline \multicolumn{6}{|c|}{ Total $\mathrm{N}$ of cases and average rates } \\
\hline 2001 & $2,599,800$ & 2 & $0.08(0.01-0.29)$ & 7 & $0.27(0.11-0.56)$ \\
\hline 2016 & $2,722,500$ & 2 & $0.08(0.01-0.28)$ & 14 & $0.51(0.28-0.86)$ \\
\hline \multicolumn{6}{|c|}{ Total $\mathrm{N}$ of cases and average rates } \\
\hline 2001-2016 & $40,557,900$ & 12 & $0.03(0.02-0.05)$ & 117 & $0.29(0.24-0.35)$ \\
\hline \multicolumn{6}{|c|}{ Males, $13-17$ years } \\
\hline 2001 & $1,615,200$ & 114 & $7.06(5.82-8.48)$ & 226 & $13.99(12.23-15.94)$ \\
\hline 2016 & $1,558,700$ & 12 & $0.77(0.40-4.34)$ & 180 & $11.55(9.92-13.36)$ \\
\hline \multicolumn{6}{|c|}{ Total $\mathrm{N}$ of cases and average rates } \\
\hline 2001-2016 & $26,186,400$ & 960 & $3.67(3.44-3.91)$ & 2940 & $11.23(10.82-11.64)$ \\
\hline \multicolumn{6}{|c|}{ Females, 5-12 years } \\
\hline 2001 & $2,475,000$ & 0 & & 6 & $0.24(0.09-0.53)$ \\
\hline 2016 & $2,594,600$ & 1 & $0.04(0-0.22)$ & 19 & $0.73(0.44-1.14)$ \\
\hline \multicolumn{6}{|c|}{ Total $\mathrm{N}$ of cases and average rates } \\
\hline 2001-2016 & $38,659,700$ & 20 & $0.01(0-0.01)$ & 152 & $0.39(0.33-0.46)$ \\
\hline \multicolumn{6}{|c|}{ Females, 13-17 years } \\
\hline 2001 & $1,531,900$ & 45 & $2.94(2.14-3.93)$ & 112 & $7.31(6.02-8.80)$ \\
\hline 2016 & $1,480,500$ & 17 & $1.15(0.67-1.84)$ & 152 & $10.27(8.70-12.03)$ \\
\hline \multicolumn{6}{|c|}{ Males, 5-12 years } \\
\hline 2001-2016 & $24,966,600$ & 394 & $1.58(1.43-1.74)$ & 1979 & $7.93(7.58-8.28)$ \\
\hline
\end{tabular}


Fig. 1 Age distribution of schizophrenia cases in individual years, 2001-2016, males and females

Fig. 2 Age distribution of non-affective psychosis cases in individual years of age, 2001-2016, males and females
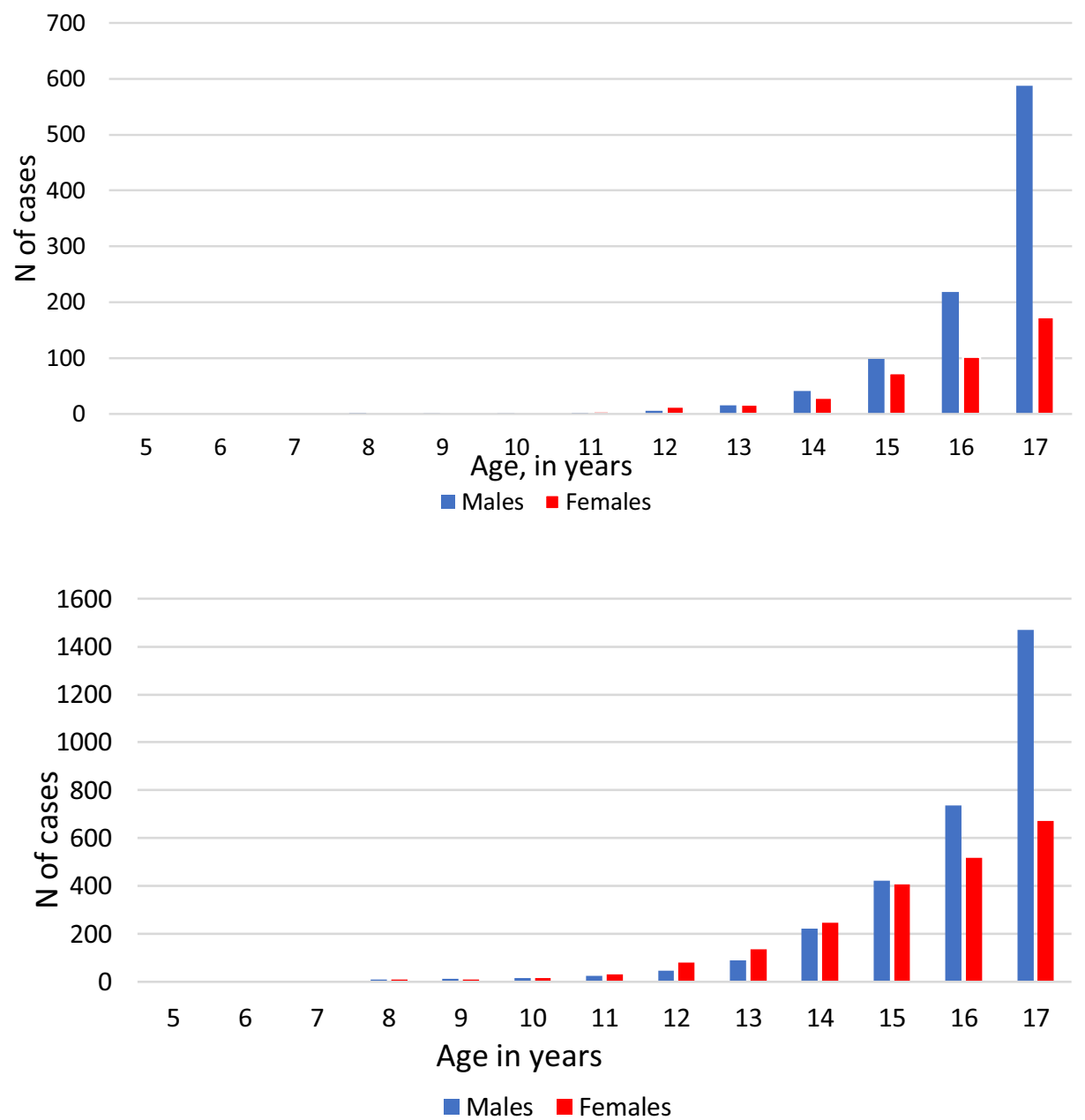

incidence rates for adolescent males with schizophrenia is not entirely clear, although judging from the timing, with the main decline occurring in the early years of the study, the introduction of the early intervention services (EIS) in 1999, with the aim of reducing admissions, could be a factor. EIS is a dedicated support service with an explicit aim to treat cases in the community, rather than hospitals with attendant problems of inpatient care in some cases. We have no explanation of why this should affect males more than females.

\section{Comparison with other studies}

Our estimates of the incidence rates of schizophrenia in children are similar to the rates reported in the literature, albeit that the literature is fairly sparse. Early studies of COS, in North Dakota in 1987, found a low prevalence rate of 1.9 per 100,000 which is consistent with the incidence rates estimated using the ORLS data [8]. In three large districts in Germany, Hafner found that admissions for schizophrenia before age 12 hardly ever occurred [9]. Similarly, this study reported only 32 cases in one and a half decades in the whole of England. Likewise, a nationwide study from Denmark, with a population around 5 million, showed COS to be very rare with 4 admissions before 13 years and 28 before 15 years of age between 1970 and 1993 [10]. A survey of UK and Irish child and adolescent psychiatrists reported 8 cases of schizophrenia below the age of 14 , and estimated a low incidence rate in the range between 0.21 and 1 per 100,000 in children aged 10-14 [11].

Our results confirm the very low rates of admission for COS with an increase in schizophrenia admissions during adolescence. Retrospective surveys indicate that less than $1 \%$ of all schizophrenic disorders manifest themselves before age 10 , and $4 \%$ before age 15 [12]. The relation between COS and autism has been described in the literature, with reports of 30-50\% of COS patients having autism [13], similar to the $50 \%$ among females reported here. As yet, there have been no studies indicating regional variations in the incidence of COS, as is well documented for schizophrenia in older age groups [14]. Further research on geographical variation in COS is needed.

An overall higher rate of schizophrenia in males has been observed [15], although there are fewer gender differences reported in $\operatorname{COS}[16,17]$. However, male patients were 
reported to develop COS at younger ages than females [15, 16]. A Danish register study reported on long-term trends in schizophrenia incidence in people under 18 years, and found that over the period 1971-2010, the incidence rates declined in males and increased in females [17]. These findings are similar to our findings on the reduction in EOS incidence in males. A later Danish study confirmed the excess of schizophrenia spectrum disorders in adolescent females versus males, with rates at $0.76 \%$ (95\% CI, $0.72 \%-0.80 \%$ ) vs $0.48 \%$ (95\% CI, $0.39 \%-0.59 \%$ ), respectively [18]. We found more cases of COS in females than in males, but no significant difference in incidence rates. There were no details of pubertal status; however, this switch to a male predominance occurs over the normal pubertal age.

In this study, we found between $22-28 \%$ of those with COS and 13-19\% with EOS were Black (Table 1); according to the most recent census $3.3 \%$ of the total population of England and Wales are Black [19], suggesting a higher proportion of Black minorities in those with schizophrenia. An excess of schizophrenia cases in Black minorities appears common to all age groups, with similar findings reported in adults [20].

\section{Strengths and limitations}

Using a large national dataset of electronic patient records to study schizophrenia in children, we identified the largest number of cases of COS to date. It is clear that with such low incidence rates, general population surveys might have a limited value. Early studies were hampered by not only the varied presentation of COS, but variable diagnostic criteria [21]. Clinical surveys have limitations-notably, sampling bias and non-standardised diagnosis. Indeed, recent work suggests that not using standardised interviews leads to an underestimate of the rates of early-onset schizophrenia, especially in cases with intellectual disability and neurodevelopmental disorders [22]. The validity of Hospital Episode Statistics for identifying cases of schizophrenia in adults is high, with positive predictive value of $90 \%$ [23]. To date, however, there are no similar validation studies for schizophrenia in children.

In the historical ORLS dataset, the psychiatric-service counts were only available in standard 5-year age groups. We had to report the number of events and incidence rates for schizophrenia for the age group 5-14 years.

The hospital data are likely to underestimate the true incidence of psychiatric conditions in the population. However, schizophrenia under 13 years is a severe disorder, often presenting with florid psychopathology, making it more likely that children with schizophrenia are admitted for investigation and treatment. Thus, the rates of admission for COS are likely to approximate the true population incidence rates. The methodology does not allow an assessment of age of true onset, so it is possible that some COS cases could have been first identified as admissions in adolescence or early adulthood. Significant national variation in COS geography is indicated by the fact that nearly one-third of cases of COS in this study came from London, which is disproportionate to its population size, comprising about $15 \%$ of the English population of 5 to 12 year olds (the total average population of England in the corresponding age group in 2001-2016 was $4,951,100$ vs London 760,078 ) and $14 \%$ of the 13 to 17 (3,197,063 vs 450,346, respectively). Even allowing for higher rates of childhood psychosis seen in urban settings [24], this suggests possible differential use of health services or variable diagnostic practises geographically.

In considering the decline in admissions for schizophrenia in adolescent males, we note that there has been no change in the diagnostic system, ICD-10 in use throughout. It is possible that psychiatrists may have become more reluctant to make the specific diagnosis of schizophrenia in the more recent years. Making a diagnosis of COS is complex: psychotic symptoms in childhood are relatively common. UK Data from the Avon Longitudinal Study of Parents and Children (ALSPAC) birth cohort reveal a 6-month period prevalence of narrow psychosis-like symptoms in 11 years old to be 5.6\% (95\% CI 5.1-6.2) [25]. Furthermore, these symptoms are not specific for schizophrenia [26]. Making the diagnosis, therefore, requires expertise to avoid the high rate of false positives involving transient psychotic states [27]. However, the diagnosis of schizophrenia in children and adolescence, once made, is stable [28].

Psychiatrists are likely to face considerable difficulties in making a diagnosis of schizophrenia in this age group because of uncertainties, including considerable symptom overlap with pervasive developmental disorders, especially in males [16]; stigma, and negative connotation and perceived lack of diagnostic validation attributed to the diagnosis of schizophrenia [29]. Indeed, there is evidence from early intervention services of a very long delay of making the diagnosis of first episode psychosis in adolescence [30]. All these factors point to a possible failure to make a diagnosis of COS, and under-reporting, which could contribute to the generally low reported rates of COS. We reported that about $80 \%$ of COS patients had a previous hospital admission for other psychiatric conditions prior to the first record of schizophrenia, which is consistent with the findings from a Danish national study, showing an increased risk of schizophrenia following any previous psychiatric admission [31].

An alternative explanation for the low rate of admissions for COS could be that prodromal and comorbid cases are diagnosed and admitted for different reasons. There is a recognised link between childhood psychiatric disordersespecially opposition defiant disorder, anxiety, and attention deficit hyperactivity disorder-and the later development of schizophrenia [31]. A further caution is the diagnostic issue 
arising from the relationship of autistic spectrum disorders to non-affective psychosis [13].

In England, the proportion of beds in the private or independent sector is increasing. This suggests that our figures for EOS are likely to be an underestimate; however, this does not apply to COS, as in the UK, the private sector does not provide psychiatric inpatient care for children (32).

In conclusion, this is the largest epidemiological study of schizophrenia diagnosed before the age of 13 years. Our findings confirm that childhood-onset schizophrenia is rare, but with age, it rises to become one of the most common and costly psychiatric disorders in adulthood. These figures may help guide the necessary care and management provisions for this serious mental disorder, as well as inform and stimulate further research into this condition.

Supplementary Information The online version contains supplementary material available at https://doi.org/10.1007/s00787-021-01817-3.

Authors contribution statement OS, MJG, and AJ planned and designed the study. MJG directed the building and analysis of the ORLS dataset. OS did the all-England analyses. AJ wrote the first draft. OS developed and completed the manuscript. MJG and UH contributed to the manuscript writing. All authors had access to data and approved the final manuscript.

Funding The project did not receive specific funding. The work of OS was supported by the NIHR Oxford Biomedical Research Centre and by Health Data Research UK.

Availability of data and materials Raw data were provided by NHS Digital. Derived data supporting the findings of this study are available from the corresponding author OS upon reasonable request.

Code availability Analysis was done using the SAS Management Studio code developed by the UHCE IT team, and not available as an open source code.

\section{Declarations}

Conflict of interest Authors have no conflicts of interest to disclose.

Open Access This article is licensed under a Creative Commons Attribution 4.0 International License, which permits use, sharing, adaptation, distribution and reproduction in any medium or format, as long as you give appropriate credit to the original author(s) and the source, provide a link to the Creative Commons licence, and indicate if changes were made. The images or other third party material in this article are included in the article's Creative Commons licence, unless indicated otherwise in a credit line to the material. If material is not included in the article's Creative Commons licence and your intended use is not permitted by statutory regulation or exceeds the permitted use, you will need to obtain permission directly from the copyright holder. To view a copy of this licence, visit http://creativecommons.org/licenses/by/4.0/.

\section{References}

1. Rapoport JL, Giedd JN, Gogtay N (2012) Neurodevelopmental model of schizophrenia: update 2012. Mol Psychiatry 17(12):1228-1238

2. Clemmensen L, Vernal DL, Steinhausen HC (2012) A systematic review of the long-term outcome of early onset schizophrenia. BMC Psychiatry 12:150

3. Eggers C, Bunk D (2009) Early development of childhood-onset schizophrenia. Fortschr Neurol Psychiatr 77(10):558-567

4. NICE. Psychosis and schizophrenia in children and young people: recognition and management. www.nice.org.uk/CG1552013.

5. Goldacre MJ, Simmons H, Henderson J, Gill LE (1988) Trends in episode based and person based rates of admission to hospital in the Oxford record linkage study area. Br Med J (Clin Res Ed) 296(6621):583-585

6. Russell AT (1994) The clinical presentation of childhood-onset schizophrenia. Schizophr Bull 20(4):631-646

7. Werner S, Malaspina D, Rabinowitz J (2007) Socioeconomic status at birth is associated with risk of schizophrenia: populationbased multilevel study. Schizophr Bull 33(6):1373-1378

8. Burd L, Kerbeshian J (1987) A North Dakota prevalence study of schizophrenia presenting in childhood. J Am Acad Child Adolesc Psychiatry 26(3):347-350

9. Hafner H, Nowotny B (1995) Epidemiology of early-onset schizophrenia. Eur Arch Psychiatry Clin Neurosci 245(2):80-92

10. Thomsen PH (1996) Schizophrenia with childhood and adolescent onset-a nationwide register-based study. Acta Psychiatr Scand 94(3):187-193

11. Tiffin PA, Kitchen CE (2015) Incidence and 12-month outcome of childhood non-affective psychoses: British national surveillance study. Br J Psychiatry 206(6):517-518

12. Remschmidt HE, Schulz E, Martin M, Warnke A, Trott GE (1994) Childhood-onset schizophrenia: history of the concept and recent studies. Schizophr Bull 20(4):727-745

13. Rapoport J, Chavez A, Greenstein D, Addington A, Gogtay N (2009) Autism spectrum disorders and childhood-onset schizophrenia: clinical and biological contributions to a relation revisited. J Am Acad Child Adolesc Psychiatry 48(1):10-18

14. McGrath J, Saha S, Welham J, El Saadi O, MacCauley C, Chant D (2004) A systematic review of the incidence of schizophrenia: the distribution of rates and the influence of sex, urbanicity, migrant status and methodology. BMC Med 2:13

15. Jongsma HE, Gayer-Anderson C, Lasalvia A, Quattrone D, Mule A, Szoke A et al (2018) Treated Incidence of Psychotic Disorders in the Multinational EU-GEI Study. JAMA Psychiat 75(1):36-46

16. Ordonez AE, Loeb FF, Zhou X, Shora L, Berman RA, Broadnax DD et al (2016) Lack of Gender-Related Differences in Childhood-Onset Schizophrenia. J Am Acad Child Adolesc Psychiatry 55(9):792-799

17. Okkels N, Vernal DL, Jensen SO, McGrath JJ, Nielsen RE (2013) Changes in the diagnosed incidence of early onset schizophrenia over four decades. Acta Psychiatr Scand 127(1):62-68

18. Dalsgaard S, Thorsteinsson E, Trabjerg BB, Schullehner J, PlanaRipoll O, Brikell I et al (2019) Incidence rates and cumulative incidences of the full spectrum of diagnosed mental disorders in childhood and adolescence. JAMA Psychiat 77(2):155-164

19. Office for National Statistics (2011) 2001 Census aggregate data (Edition: May 2011). UK Data Service. https://doi.org/10.5257/ census/aggregate-2001-2Statistics

20. Tortelli A, Errazuriz A, Croudace T, Morgan C, Murray RM, Jones PB et al (2015) Schizophrenia and other psychotic disorders in Caribbean-born migrants and their descendants in England: systematic review and meta-analysis of incidence rates, 19502013. Soc Psychiatry Psychiatr Epidemiol 50(7):1039-1055 
21. Remschmidt H (1988) Schizophrene Psychosen im Kindesalter. In: Kisker KP, Lauter H, Meyer J-E, Mtiller CS (eds) Psychiatrie der Gegenwart 7: Kinder und Jugendpsychiatrie. Springer, New York, pp 89-11

22. Dor-Nedonsel E, Menard ML, Fernandez A, Sakarovitch C, Fontas E, Salle-Collemiche X et al (2020) Early-Onset Schizophrenia in a paediatric population of French psychiatric and medico-social care centres: A cross sectional study. PLoS ONE 15(7):e0236241

23. Davis KAS, Bashford O, Jewell A, Shetty H, Stewart RJ, Sudlow CLM et al (2018) Using data linkage to electronic patient records to assess the validity of selected mental health diagnoses in English Hospital Episode Statistics (HES). PLoS ONE 13(3):e0195002

24. Newbury J, Arseneault L, Caspi A, Moffitt TE, Odgers CL, Fisher HL (2016) Why are children in urban neighborhoods at increased risk for psychotic symptoms? Findings from a UK Longitudinal Cohort Study. Schizophr Bull 42(6):1372-1383

25. Horwood J, Salvi G, Thomas K, Duffy L, Gunnell D, Hollis C et al (2008) IQ and non-clinical psychotic symptoms in 12-yearolds: results from the ALSPAC birth cohort. Br J Psychiatry 193(3):185-191

26. Fisher HL, Caspi A, Poulton R, Meier MH, Houts R, Harrington $\mathrm{H}$ et al (2013) Specificity of childhood psychotic symptoms for predicting schizophrenia by 38 years of age: a birth cohort study. Psychol Med 43(10):2077-2086

27. Stayer C, Sporn A, Gogtay N, Tossell JW, Lenane M, Gochman P et al (2005) Multidimensionally impaired: the good news. J Child Adolesc Psychopharmacol 15(3):510-519

28. Hollis C (2000) Adult outcomes of child- and adolescent-onset schizophrenia: diagnostic stability and predictive validity. Am J Psychiatry 157(10):1652-1659

29. Guloksuz S, Os J (2018) Renaming schizophrenia: $5 \times 5$. Epidemiol Psychiatr Sci. 25:1-4

30. Birchwood M, Bryan B, Jones-Morris N, Kaambwa B, Lester H, Richards. J, et al. EDEN: Evaluating the development and impact of Early Intervention Services (EISs) in the West Midlands. A Report for the NHS Service Delivery and Organisation National R \& D Programme. London School of Hygiene \& Tropical Medicine; 2006.

31. Maibing CF, Pedersen CB, Benros ME, Mortensen PB, Dalsgaard S, Nordentoft M (2015) Risk of Schizophrenia Increases After All Child and Adolescent Psychiatric Disorders: A Nationwide Study. Schizophr Bull 41(4):963-970

32. Children and Young People's Mental Health: The State of the Nation,. Education Policy Institute 2016. 